\title{
İşsizlik ile Enflasyon Arasındaki İlişki: Türkiye'deki Düzey-2 Bölgeleri İçin Ampirik Bir Analiz
}

\author{
Efdal POLAT
}

\begin{abstract}
$\ddot{O} Z$
İssizlik ve enflasyon oranları makroekonomik göstergeler arasında önemli bir yere sahiptir. Çünkü her iki göstergedeki olumlu veya olumsuz bir değişme ülke ekonomisini dolayl ya da doğrudan bir şekilde etkilemektedir. Bu bağlamda, çalışmanın amacı Türkiye'de bulunan Düzey-2 bölgeleri için işsizlik ve enflasyon arasındaki ilişkiyi analiz etmektir. 2008-2017 yılları arası verileri kapsayan çalışmada işsizlik ve enflasyon arasındaki ilişsiyi tespit edebilmek için panel veri analizi kullanılmıştır. Bu kapsamda çalışmada kullanılacak yöntemin tahmini için F testi, Breusch-Pagan $L M$ ve Honda testleri uygulanmıştır. Uygulanan bu testler sonucunda sabit etkiler yönteminin çalışmanin analizi için daha uygun olduğu sonucu elde edilmiştir. Daha sonra ise değişen varyans ve otokorelasyon sorununun olup olmadığı analiz edilmiştir. Sabit etkiler modeli esas alınarak yapılan en küçük kareler tahmin sonucuna göre işsizlik ve enflasyon arasında negatif bir iliş̧i tespit edilmiştir.
\end{abstract}

Anahtar Kelimeler: Enflasyon, İssizlik, Panel Veri Analizi, Türkiye, Düzey-2 Bölgeleri JEL Sinıflandırmast: E31, E24, C23

\section{The Relation Between Unemployment and Inflation: An Empirical Analysis for NUTS-2 Regions in Turkey}

\begin{abstract}
Unemployment and inflation rates have an important place among macroeconomic indicators. Because both two positive or negative change of indicators affect the country's economy directly or indirectly. In this context the aim of study is to analyze the relation between unemployment and inflation for NUTS-2 regions in Turkey. In this study, panel data analyze is employed to establish the relation between unemployment and inflation by using the data between 2008-2017. In this respect, $F$ test, Breusch-Pagan LM and Honda tests are applied to estimate the method of the study. As a result of these tests, it was found that the fixed-effects method was more suitable for the analysis of the study. Then, it is analyzed whether the heteroscedasticity and autocorrelation problem exist. According to the results of the least squares estimation based on fixed-effects model, a negative relationship was found between unemployment and inflation.
\end{abstract}

Key Words: Inflation, Unemployment, Panel Data Analyze, Turkey, NUTS-2 Regions

JEL Classification: E31, E24, C23

\section{GİRIŞ}

Makroekonomik göstergelerde istikrarın sağlanması ülke ekonomileri için önem arz etmektedir. Özellikle fiyat istikrarının sağlanabilmesi yani enflasyon oranının hedeflenen düzeyde tutulması ve istihdamın arttırılması ya da işsizliğin azaltılması hükümetlerin ekonomi politikaları içerisinde önemli yer tutmaktadır. Zira hem yüksek enflasyon hem de yüksek işsizlik ülke ekonomileri için

\footnotetext{
* Dr., Bağımsız Araştırmacı, efdalpolat@ gmail.com, ORCID bilgisi: 0000-003-0178-0128,
}

(Makale Gönderim Tarihi: 25.03.2019 / Yayına Kabul Tarihi:26.08.2019)

Doi Number: 10.18657/yonveek544446

Makale Türü: Araştırma Makalesi 
istenmeyen bir durumdur. Çünkü her iki değiş̧kendeki olumsuz bir gelişme dolaylı olarak üretimi, tüketimi, bireylerin refahını dolayısıyla da ülke ekonomisini olumsuz yönde etkileyecektir.

Enflasyon ve işsizlik konusundaki sorunlar geçmişten günümüze kadar tartışılan konuların başında yer almıştır. Dolayısıyla iki değiş̧ken arasındaki ilişkiyi açıklamaya yönelik hem teorik hem de ampirik birçok çalışma yapılmıştır. Enflasyon ve işsizlik arasındaki ilişkiyi açıklamaya yönelik yapılan çalışmalarda her ne kadar A. W. Phillips'in 1958 yılında yapmış olduğu çalışma ön plana çıksa da Phillips'ten önce bazı çalışmaların yapıldığı görülmektedir. Humprey (1985a, 1985b)'in yapmış olduğu çalışmalarda aslında enflasyon ve işsizlik arasındaki ilişkiyi teorik olarak David Hume (1752) ve Henry Thornton (1802)'un çalışmalarında değinildiği, ampirik olarak ise; enflasyon ve işsizlik arasındaki ilişkiyi istatistiksel olarak Irving Fisher (1926)'in "A Statistical Relationship Between Unemployment and Price Changes" isimli çalışmasında, ekonometrik olarak Jan Tinbergen (1936)' in "An Economic Policy for 1936" isimli makalesinde ve Lawrence Klein ve Arthur Goldberger (1955)' in "An Econometric Model of the United States, 1929-1952" isimli çalışmalarında analiz edildiği ifade edilmiştir. Son olarak ise enflasyon ve işsizlik arasındaki ilişkinin dağılım diyagramının A.J. Brown (1955) tarafindan yapilan "The Great Inflation 1939-1951" isimli çalışmasında çizildiği, iki değişken arasındaki ilişkinin bir eğri olarak gösteriminin ise Paul Sultan (1957)'ın “Labor Economics” isimli yapmış olduğu çalışmada yer aldığ ifade edilmektedir (Humprey, 1985a: 3;Humprey, 1985b: 17-24). Görüldüğü üzere A. W. Phillips'ten önce enflasyon (ya da fiyat değişmeleri) ve işsizlik arasında çalışmalar yapılmış ancak iki değişken arasındaki ilişkinin açıklanmasına yönelik A. W. Phillips'in 1958 yılında yapmış olduğu "The Relation Between Unemployment and the Rate of Change of Money Wage Rates in the United Kingdom, 1861-1957" isimli çalışma günümüzde ilgi uyandırmıştır. Bu çalışmalardan sonra Phillips eğrisine yönelik birçok çalışma yapılmış ve teori geliştirilmeye çalışılmıştır.

Bu çalışmalardan yola çıkarak Türkiye için de birçok çalışma yapılmıştır ve hala yapılmaktadır. Bu çalışmaların bazısında enflasyonla işsizlik arasında ters yönlü ilişki bulunurken, bazılarında ise herhangi bir ilişki bulunamamıştır. Türkiye'deki Düzey-2 bölgeleri için işsizlik ve enflasyon arasındaki ilişkiyi açıklamayı amaçlayan bu çalışma, bölgesel bazda yapıldığ için diğer çalışmalardan farklılık göstermektedir. Çalışma 2008-2017 arasını kapsamaktadır. Çalışmanın birinci bölümünde Phillips eğrisine yönelik yapılmış teorik çerçeve anlatılmıştır. İkinci bölümde konuyla ilgili daha önce yapılmış yerli ve yabancı literatüre yer verilmiştir. Üçüncü bölümde çalışmada kullanılan verilere ve yönteme yer verilirken, dördüncü bölümde ise elde edilen bulgular tartışılmıştır.

\section{TEORIKK ARKA PLAN}

Daha önce de değinildiği üzere Phillips'in çalışmasından önce enflasyon ve işsizlik arasında ilişkiyi analiz etmeye yönelik ampirik çalışmalar yapılmıştır. İstatistiki anlamda ilk çalışma Irving Fisher tarafından 1926 yılında yapılmıştır. Irving Fisher "A Statistical Relation between Unemployment and Price Changes" 
isimli çalışmasında fiyat değişmeleri ile işsizlik arasındaki ilişkiyi istatistiksel olarak analiz etmiştir. Fisher, 1915-1925 yıllarını kapsayan ve ABD için yapmış olduğu çalışmasında dolar değerindeki değişim oranı ile işsizlik arasında $\% 90$ gibi yüksek bir kolerasyon olduğu sonucunu elde etmiştir (Fisher, 1973: 497). Fisher işsizlik ile fiyat değişmeleri arasındaki ilişkiyi şu şekilde açıklamaktadır. Dolar değer kaybettiğinde ya da fiyat seviyesi yükseldiğinde işverenlerin ortalama karı da bu yükseliş hızında artacaktır. Ancak giderler tahvil faizleri gibi sözleşmeye bağlı sabit tutarlardan oluştuğu için fiyat seviyesindeki artış oranından daha az bir oranda etkilenecektir. Dolayısıyla iş adamının karı artacaktır. İstihdam ise bir süre daha teşvik edilecektir. Ancak enflasyonun uzun sürmesi yaşam maliyetlerini arttıracaktır. Öte yandan fiyatların düşmesi harcamaların gerisinde kaldığı için işverenin karı azalacak, iflaslar artacak ve insanlar işten çıkarılacaktır. Bundan dolayı işsizlik ile doların satin alma gücü arasında bir ilişkinin olduğu ifade edilmektedir (Fisher, 1973: 498).

Parasal ücret ile istihdam arasındaki ilişkiyi ekonometrik denklemler yardımıyla ilk olarak Jan Tinbergen analiz etmiştir. Tinbergen "An Economic Policy for 1936" adlı çalışmasında, Hollanda'ya ait 1923-33 dönemine ait verileri kullanmıştır. Çalışmada $\mathrm{dW}=0.16 \mathrm{E}+0.27 \mathrm{dP}_{-1}$ sonucu elde edilmiştir. Eşitlikte bulunan $\mathrm{dW}$, parasal ücretlerdeki değişmeyi, $\mathrm{E}$, normal seviyesine göre istihdam1 ve gecikmeli fiyat değişimini, $\mathrm{dP}_{-1}$ değişkeni ise ücretlerin yaşam pahalılığına uyum faktörünü ifade etmektedir. Elde edilen eşitliğe göre istihdamdan ücret enflasyonuna doğru bir nedensellik ilişkisi söz konusudur (Humprey, 1985b: 21; Büyükakın, 2008: 135).

Lawrence Klein ve Arthur Goldberger ise 1955 yılında yaptıkları " $A n$ Econometric Model of the United States, 1929-1952" adlı çalışmalarında $\Delta \mathrm{W}=4.11-0.74 \mathrm{U}+0.52 \Delta \mathrm{P}-1+0.54 \mathrm{t}$ sonucunu elde etmiştir. Eşitlikte bulunan $\mathrm{U}$, toplam işsizliği, $\mathrm{t}$ ise zaman trendini ifade etmektedir. Diğer değişkenler Tinbergen denklemindeki değişkenler ile aynıdır. Klein ve Goldberger arz ve talep kanunu mantığ 1 çerçevesinde, eşitlikte yer alan sonucu elde ettiklerini ifade etmiştir. Şöyle ki, parasal ücret oranları işgücü piyasasındaki arz ve talep fazlalığına göre hareket etmektedir. Yüksek işsizlik oranı yüksek arz fazlalığını, friksiyonel işsizliğin altında bulunan düşük işsizlik oranı ise yüksek talep fazlalığına yol açmaktadır.

Phillips eğrisine benzer ilk çizimler ise A.J. Brown'ın ve Paul Sultan'ın çalışmalarında görülmektedir. A.J. Brown, 1955 yılında yayınlanan "The Great Inflation 1939-1951" adl eserinde, 1880-1914 ve 1920-1951 dönemi için İngiltere'deki, 1921-1948 dönemi için ise ABD'deki ücret enflasyonu ile işsizlik oranları verileri yardımıyla Phillips eğrisine benzeyen ilk istatistiki dağılım şemasını sunmuştur. Çalışmada, ücretlerin yüksek işsizlik oranlarından daha düşük oranlarda değişmesine bağlı olarak, iki değişken arasında doğrusal olmayan ters yönlü bir ilişki tespit edilmiştir (Humprey, 1985b: 22). Paul Sultan'ın 1957 yılında yayınlanan "Labor Economics" isimli ders kitabında, enflasyon ile işsizlik oranları arasında istikrarlı bir değiş-tokuş (trade-off) ilişkisinin olduğu ilk grafiksel gösterim yapılmıştır. Sultan (1957)'e göre, eğer işsizlik oranı, işgücünün $\% 2$ 'sinden daha az olursa enflasyon sorunuyla karşı karşıya kalınacaktır. İşsizlik 
oranı \%6'dan fazla olursa bu defa da ciddi manada denflasyon sorunu ortaya çıkacaktır (Humprey, 1985b: 23; Büyükakın, 2008: 135).

$\mathrm{Bu}$ çalışmalardan daha sonra işsizlikle enflasyon arasındaki ilişkiyi açıklamaya çalışan eser, A. W. Phillips tarafından 1958 yılında yapılan "The Relation Between Unemployment and the Rate of Change of Money Wage Rates in the United Kingdom, 1861-1957” isimli çalışmadır. Phillips çalışmasında işsizlik ile parasal ücret oranlarındaki değişim oranı arasında doğrusal olmayan (nonlinear) bir ilişki tespit etmiştir. Phillips'e göre, işgücü talebi yüksek ve işsiz sayısı az olduğunda, işverenler geçerli ücretlerin üzerinde bir ücretle teklif sunarak her bir firma veya endüstriden emek istihdam edeceklerdir. Dolayısıyla ücret oranları hızlı bir şekilde artacaktır. Tersine, işgücü talebi düşük ve işsizlik oranı yüksek olduğunda, işçiler geçerli ücretlerin altında çalışmak istemeyeceğinden, ücret oranları çok yavaş bir şekilde düşecektir. Bundan dolayı işsizlik ve parasal ücret oranlarındaki değişim oranı arasında yüksek derecede doğrusal olmayan (nonlinear) bir ilişki ortaya çıkmıştır (Phillips, 1958: 283). Phillips'in elde ettiği sonuçlara göre, eğer yıllık verimlilik artış1 \%2 seviyesinde gerçekleşirse, ürün fiyatlarında istikrar sağlayabilmek için işsizlik oranının yaklaşık $\% 2,5$ civarında olması gerekmektedir. Phillips, parasal ücret oranlarında istikrarın sağlanabilmesi için ise işsizlik oranının \%5,5 seviyesinde olması gerektiğini ifade etmiştir. Phillips'e göre, bu bulgular kesin sonuçlar içermemektedir. Dolayısıyla işsizlik, parasal ücret oranları, fiyatlar ve verimlilik arasındaki ilişkileri açıklamaya yönelik daha detaylı analizlerin yapılması gerektiği Phillips tarafından belirtilmiştir (Akkuş, 2012:107).

Phillips eğrisinin teorik olarak geçerliliğine destek sunan en önemli çalışma Richard G. Lipsey (1960) tarafından yapılmıştır. Lipsey, Phillips'in yapmış olduğu çalışmayı yeniden analiz etmiştir. Lipsey (1960) çalışmasında emek talebi fazlası (d-s/s) ile parasal ücret değişmeleri (w) arasındaki ilişkiyi ve emek talebi fazlası ile işsizlik (u) arasındaki ilişkiyi açıklamaya çalışmıştır. Lipsey, ücretlerin değişme hızının işgücünün bir oranı olarak artan talebe bağlı olduğunu ifade etmektedir. Yani aşırı emek talebi ile parasal ücret değişmeleri arasında doğru yönlü bir ilişkinin olduğunu ifade etmektedir. Bunun yanı sıra emek talebi fazlası ile işsizlik arasında ise ters yönlü bir ilişki söz konusudur. Lipsey'e göre, arz ve talep doğruları arasında bir denge söz konusu olduğunda piyasada oluşan ücretler oranından insanlar çalışmak isteyecektir. Ancak herhangi bir sebepten dolayı işçilerin iş değiştirmek istemeleri friksiyonel işsizlik durumunu doğuracaktır. Emek talebinde bir artış olduğunda ise iş bulmak kolaylaşacağı için işsizlik oranı azalacaktır (Lipsey, 1960: 13-16). Sonuç olarak, Lipsey açılamalarını emek piyasasındaki talep fazlalığına dayandırarak, Phillips Eğrisi analizini teorik bir temele oturtmuştur (Büyükakın, 2008: 139).

Phillips, analizinde parasal ücretlerdeki değişim oranı ile işsizlik oranı değişkenleri arasındaki ilişkiyi açıklarken, Paul Samuelson ve Robert Solow Phillips'in analizinde kullandığı parasal ücretlerdeki değişim oranı yerine fiyat artışlarını (yani enflasyon oranını) kullanarak Phillips eğrisini yeniden incelemişlerdir. Çalışmalarında ABD için enflasyon oranı ve işsizlik oranı 
arasındaki ilişki "modifiye edilmiş Phillips Eğrisi" olarak tanımlanmıştır (Samuelson ve Solow, 1960: 192). Modifiye edilmiş Phillips eğrisine göre, parasal ücretlerin ABD’nin \%2,5 seviyesindeki verimlilik artışından fazla olmaması gerekmektedir. Böylesi bir fiyat istikrarının maliyeti \%5-6 arasında bir işsizlik oranına katlanmaktır. İşsizlik oranının \%3'e düşmesi durumunda ise fiyat artış oranı \%4-5 arasında olacaktır. Yazarlara göre bu yüksek fiyat artışı, gelecekte yüksek istihdam ve üretimin maliyeti olarak ortaya çıkacaktır (Samuelson ve Solow, 1960: 192). Samuelson ve Solow yapmış oldukları analizin kısa vadeli ifadeler içerdiği, dolayısıyla uzun vadede enflasyon ile işsizlik arasındaki ilişkinin aynı sonucu vermesinin yanlış olduğunu ifade etmektedir. Çünkü yakın gelecekte uygulanacak politikalar modifiye edilmiş Phillips eğrisinde değişikliklere yol açabilecektir (Samuelson ve Solow, 1960: 193).

1960'lı y1llarda Phillips eğrisinin istikrarlı olduğu ve tüm zamanlar için geçerli olduğu dolayısıyla güvenilir bir politika aracı olduğu varsayılmaktaydı. Ancak, 1960'lı yılların ortalarında ABD için yapılan çalışmalarda değiş-tokuş (trade-off) ilişkisinin istikrarlı olmadığı ve 1970'li yılların başında hem enflasyon hem de işsizlik oranlarında artış yaşanmasıyla ortaya çıkan stagflasyon sorunu, Phillips eğrisinin yeniden sorgulanmasına yol açmıştır (Büyükakın, 2008: 143;Akkuş, 2012: 113-114). 60 yılların sonlarına doğru E. S. Phelps (1967) ve Friedman $(1968,1977)$ çalışmalarında enflasyonist beklentilerin Phillips eğrisi analizine dahil edilmesiyle Phillips eğrisinin zaman içinde yer değiştirebileceğini ifade etmiştir (Büyükakın, 2008: 144).

Edmund S. Phelps, 1967 y1lında yayınlanan "Phillips Curves, Inflation Expectations, And Optimal Employment Over Time" adlı çalışmasında uyarlanabilir (adaptif) beklentiler kapsamında Phillips eğrisini analiz etmiştir. Phelps çalışmasında, toplam istihdamın zaman içerisindeki değişimini dinamik bir makro model çerçevesinde sunmaya çalışmıştır. Beklenen enflasyon oranı ve toplam istihdamın seyrinden fiili enflasyon oranının elde edilebileceğini ifade eden Phelps, çalışmasında ücret değişim oranından ziyade, beklenen enflasyon oranındaki değişikliklere bağlı olarak değişen, fiyat değişim oranını ele almıştır. Ayrıca beklenen enflasyon oranın, fiili enflasyon oranına kademeli olarak uyum sağlayacağı dinamik bir mekanizma kapsamında, optimal fayda veya istihdam yolu kavramları açıklanmıştır. Phelps, optimal fayda veya istihdam yolunu, Phillips eğrisindeki değişmeyi düzenleyen uyarlanabilir (adaptif) beklentiler sistemine bağlı olarak sosyal fayda toplamını en üst düzeye çıkaran yol olarak tanımlanmaktadır (Phelps, 1967: 254). Phelps enflasyon oranının, fayda oranına ve beklenen enflasyon oranına bağl olduğunu ifade etmektedir (Phelps, 1967: 261). Phelps, adaptif bekleyişleri modeline ilave ederek Phillips eğrisine dinamik bir çerçeve kazandırmıştır. Bu nedenle Phelps, Phillips eğrisinin Keynesyen iktisatçıların varsaydığ 1 gibi istikrarsız olduğunu izah etmiştir. Phelps'e göre, beklentilerdeki değişiklik Phillips eğrilerinin yukarı kaymasına yol açacaktır. Ayrıca Phillips eğrisinin istikrarlı olduğu tek nokta, fiili enflasyon ile beklenen enflasyon oranının birbirine eşit olduğu ve beklenen enflasyon oranının değişmediği işsizlik seviyesine denk gelen ve dikey eksene parelel olan Phillips 
eğrisidir. Beklenen enflasyon oranının değişmediği işsizlik oranı "denge işsizlik" oranı olarak adlandırılmaktadır. Sonuç olarak Phelps, enflasyon ve işsizlik oranları arasındaki değiş-tokuş ilişkisinin kısa dönemli bir analiz olduğunu açıklamıştır (Akkuş, 2012: 124).

Phillips eğrisini adaptif bekleyişler çerçevesinde anlatan diğer bir çalışma Milton Friedman tarafından yapılmıştır. Friedman 1968 yılında yayınladığı "The Role of Monetary Policy (Para Politikasının Rolü)" isimli çalışmada para politikası ile işsizlik oranı arasındaki ilişkiyi açıklamıştır. Friedman'a göre, reel ücretlerin dengede olduğu herhangi bir dönemde piyasada bir miktar işsizlik olabilecektir. Bu işsizlik seviyesinde, sermaye oluşumu, teknolojik gelişmeler gibi uzun dönemli eğilimler devam ettiği sürece reel ücret oranları normal bir şekilde artmaya devam edecektir. İşsizlik oranlarının daha da düşmesi sonucunda aşırı bir emek talebi oluşacağından, reel ücret oranlarının artması yönünde bir baskı ortaya çıkacaktır. Yüksek işsizlik oranlarında ise piyasada aşırı emek arzı oluşacağından reel ücret oranları azalmaya başlayacaktır. Yani iç piyasada oluşan kusurlar, talep ve arzdaki stokastik değişkenlik, iş imkanları ve iş ilanları hakkında bilgi toplamanın maliyeti gibi Walrasian genel denge denklemleri kapsamında ortaya konan bir "doğal işsizlik oranı" söz konusudur. Friedman aslında bu anlattıklarının Phillips'in yapmış olduğu çalışmaya benzediğini ifade etmiştir. Ancak Phillips'in çalışmasında nominal ücretler ile doğal ücretler arasında bir ayrımın yapılmaması Friedman tarafindan bir eksiklik olarak görülmüştür (Friedman, 1968: 8).

Friedman, doğal oran hipotezinin, orijinal Phillips eğrisi yaklaşımını özel bir durum olarak içerdiğini, ifade etmektedir (Friedman, 1977: 470). Friedman'a göre enflasyon ile işsizlik arasında istikrarlı bir denge yoktur, ancak gerçeklerle tutarlı bir doğal işsizlik oranı vardır. Eğer işsizlik seviyesi doğal işsizlik oranın altına düşerse, ancak hızlanan bir enflasyonla doğal işsizlik seviyesine tekrardan ulaşılabilir (Friedman, 1977: 458).

Sonuçta hem Friedman hem de Phelps işsizlik ve enflasyon arasındaki ilişkiyi açıklamaya yönelik analizlerini adaptif beklentiler çerçevesinde yapmaktadır. Yani geçmiş dönem enflasyon deneyimleri, bireylerin gelecekteki enflasyona ilişkin beklentilerine yön verir. Ayrıca beklenen enflasyon değerleri gerçek değere adapte olana kadar hem işveren hem de işçiler fiyat ve ücret artışlarının niteliği hakkında bir aldatmacaya düşer. Dolayısıyla kısa dönemde işsizlik ve enflasyon arasında bir değiş tokuş oluşur. Fakat fiili ve beklenen enflasyon oranının eşitlendiği uzun dönemde, işsizlik ve enflasyon arasındaki değiş-tokuş ortadan kalkar (Akkuş, 2012: 125).

Phillips eğrisi analizine farklı bir yaklaşım kazandıran çalışmalar yeni klasik iktisatçılar tarafından yapılmıştır. Yeni klasik iktisatçılar Phillips eğrisini rasyonel beklentiler varsayımıyla analiz etmiştir. Rasyonel beklentiler varsayımına göre, beklentiler oluşturulurken geçmiş döneme ait bilgilerin yanı sıra cari dönem bilgileri de kullanılmaktadır. Bu nedenle beklentilerde sistematik hata mevcut değildir, yani bireyler rasyonel davrandıkları için aynı hataya tekrar düşmezler. Phillips eğrisi analizlerinde kullanılan diğer önemli bir varsayım, ücret ve fiyatların esnekliği ile ilgilidir. Walrasgil mikro genel denge analizi çerçevesinde, ücret ve 
fiyatların aşağı ve yukarı yönlü hareketli olması hem miktar hem de fiyatların ayarlanması sonucu kısa dönemde doğal işsizlik oranında dengenin kendiliğinden oluşmasını sağlar. Sonuç olarak yeni klasik iktisatçılara göre kısa dönemde enflasyonla işsizlik arasında bir değiş-tokuş bulunmamaktadır. Sadece fiili enflasyonun beklenen enflasyondan farklı olduğu bir durumda işsizlikle enflasyon arasında bir ilişki meydana gelebilir (Çevik, 2005).

\section{LITERATÜR TARAMASI}

Literatürde işsizlik ve enflasyon arasındaki ilişkiyi inceleyen birçok çalışma mevcuttur. Bu çalışmalar farklı dönemleri ve farklı ülkeleri kapsamaktadır. Dolayısıyla bu başlık altında hem Türkiye için yapılmış hem de başka ülkeler için yapılmış çalışmalara değinilmiştir.

Aşırım (1995), 1968-1994 dönemlerini kapsayan Türkiye için yapmış olduğu çalışmasında Keynesyen varsayımı destekleyen Lucas'ın çalışmasını baz almıştır. Çalışmada enflasyon oranındaki değişkenlik arttıkça üretim-enflasyon değiş tokuşunun bozulduğu sonucuna varılmıştır.

Uysal ve Erdoğan (2003), 1980-2002 yıllarını kapsayan Türkiye ekonomisine ait işsizlik oranları ile enflasyon oranları arasındaki ilişkiyi Phillips eğrisi yardımıyla analiz etmiştir. Çalışmada işsizlik oranları ile enflasyon oranları arasında negatif bir ilişkinin olduğu ve enflasyonun işsizliği etkilediği sonucuna varılmıştır.

Ewing ve Seyfried (2003) çalışmalarında doğrusal olmayan varyans modeli ile 1954 ve 1999 yılları arasındaki ABD ekonomisine ait enflasyon ve çıktı açı̆̆1 verilerini kullanarak Phillips eğrisinin geçerliliğini analiz etmiştir. Elde edilen bulgular neticesinde kısa dönemde Phillips eğrisinin geçerliliği kabul edilmiştir.

Kuştepeli (2005), Türkiye için 1980-2002 yılları arasını kapsayan çalışmasında enflasyon ile işsizlik arasındaki ilişkiyi incelemiştir. Ancak iki değişken arasında herhangi bir ilişki bulunmamıştır.

Önder (2006), Türkiye için Phillips eğrisini analiz etmiştir. 1987-2004 yılları arasını kapsayan çalışmada çoklu yapısal kırılma modeli kullanılmıştır. Türkiye Phillips eğrisinin doğrusal olmadığı sonucu elde edilmiştir.

Mayes ve Viren (2006), çalışmalarında 15 Avrupa Birliği ülkesi için 19742004 yılları arası enflasyon, bölgesel işsizlik ve sektörel gelir dağılımı arasındaki ilişkiyi incelemiştir. Analiz sonucunda $15 \mathrm{AB}$ ülkesi için enflasyon ve işsizlik arasında doğrusal olmayan bir ilişki tespit edilmiştir.

Kitov (2007), çalışmasında Avusturya ve Fransa için işsizlik, enflasyon ve işgücü arasındaki doğrusal ilişkiyi incelemiştir. Model \%90’ın üzerinde anlamlı çıkmıştır. Yani her iki ülkede de değişkenler arasında bir ilişki saptanmıştır.

Musso vd. (2009) 1970-2005 yılları arasını kapsayan çalışmalarında Euro bölgesi için enflasyon ve çıktı açığı verileriyle Phillips eğrisini analiz etmiştir. Çalışmada üç sonuç elde edilmiştir. i) 1980'lerin ortalarına doğru Euro bölgesinde enflasyon ortalamalarında şaşırtıcı bir şekilde kaymanın olduğu tespit edilmiştir. ii) 1980'lerde eğrinin eğiminde değişiklik meydana geldiği tespit edilmiştir. Eğrinin eğimindeki değişikliğin sebebi fiyatların sıklıkla ayarlanmasının enflasyon ortalamalarındaki yaratmış olduğu olumsuzluklardır. iii) sonuç olarak enflasyon ile 
çıktı açı̆̆g arasında Phillips eğrisinin geçerliliğini kanıtlayan doğrusal bir ilişki bulunamamıștır.

Korkmaz (2010), çalışmasında Yeni Keynesyen görüş bağlamında Türkiye'deki enflasyonun, geçmiş enflasyona göre mi yoksa gelecek enflasyon beklentisine göre mi belirlendiğini araştırmıştır. Araştırma yöntemi olarak melez formda oluşturulan 2AEKK yöntemi kullanılmıştır. Çalışmada Türkiye'deki enflasyonun gelecek enflasyon beklentisine göre gerçekleştiği sonucu elde edilmiştir.

Arabacı ve Eryiğit (2012), çalışmada, Hansen (1996, 2000) tarafından geliştirilen eşik regresyon modeli baz alınarak, enflasyonun oluşumunda önemli role sahip değiş̧kenlerle genişletilmiş bir Phillips Eğrisi ilişkisini analiz etmişlerdir. Elde edilen bulgular neticesinde Türkiye ekonomisinde, reel ekonomik aktivite ve enflasyon arasında istikrarlı bir istikrarsızlık olduğu ifade edilmiştir.

Bayrak ve Kanca (2013) çalışmalarında 1970-2010 yılları arasında Türkiye ekonomisi için Phillips eğrisinin geçerliliğini incelemiştir. Analizde sırasıyla birim kök ve eşbütünleşme testleri uygulanmıştır. Çalışma sonucuna göre, Türkiye ekonomisinde uzun donemde Phillips Eğrisi analizinin geçerli olmadığı ancak kısa donemde enflasyon ile işsizlik arasında bir değiş-tokuşun (trade-off) var olduğu belirlenmiştir.

Fitzgerald ve Nicolini (2014) Birleşik Devletler'de yer alan 27 büyükşehir istatistik alanı için işsizlik ve gelecekteki enflasyon oranı arasındaki ilişkiyi analiz etmiştir. 1976-2010 yılları arasını kapsayan çalışmada iki temel sonuç elde edilmiştir. Birincisi, NAIRU modelinin doğru olduğu varsayılırsa, işsizlik ve gelecekteki enflasyon arasındaki ilişkinin tanımlanması için bölgesel veriler kullanılabilir. İkinci olarak ise, işsizlik oranındaki yüzde 1'lik bir artış gelecek yıl enflasyon oranında yaklaşık olarak yüzde 0,3 puanlık bir azalışa yol açacaktır.

Alisa (2015), çalışmasında 1999-2015 arasında Rusya Federasyonu için enflasyon ve işsizlik arasındaki ilişkiyi analiz etmiştir. Enflasyondaki artışın (azalışın) işsizliği azaltmayacağı (arttırmayacağı) sonucuna ulaşılmıştır.

Tabar ve Çetin (2016), çalışmalarında Türkiye'de Phillips eğrisinin, kısa ve uzun vadede geçerliliğini analiz etmiştir. 2003-2016 dönemi aylık verilerin kullanıldığı çalışmada, Phillips eğrisinin hem kısa hem de uzun vadede Türkiye için geçerli olmadığı sonucu elde edilmiştir.

Vermeulen (2017) Güney Afrika için enflasyon ve işsizlik arasındaki ilişkiyi analiz etmiştir. Çalışmada uzun dönem analiz için 1971-2014 yılları, kısa dönem analiz için ise 2000-2015 yılları ele alınmıştır. Çalışmada kısa dönemde enflasyon ve işsizlik arasında herhangi bir ilişki bulunmazken, uzun dönemde enflasyon ve işsizlik arasında negatif yönlü bir ilişki bulunmuştur.

Karacan (2018), 2005-2018 dönemi aylık verileriyle Türkiye için Phillips eğrisini analiz etmiştir. Çalışmada enflasyon ile işsizlik arasında bir ilişki bulunamamıştır.

Karahan ve Uslu (2018), çalışmalarında Phillips eğrisini Sınır testi yaklaşımı, ARDL metodu ve Kalman Filtresi modeliyle 1996-2016 yılları için incelemiştir. Çalışmada Kalman Filtresi modeli sonuçlarına göre, işsizliğin enflasyon 
üzerindeki etkisinin enflasyon hedeflemesi rejimi uygulanmasından sonra önemli ölçüde arttığ 1 ifade edilmiştir.

Ho ve Iyke (2018) Ocak 1999-Şubat 2017 dönemini kapsayan 11 Avro bölgesinde kısa ve uzun dönem Phillips eğrisinin varlığını sınamıştır. Çalışmada doğrusallık varsayımı altında kısa ve uzun vadede Phillips eğrisinin geçerli olduğu sonucu elde edilmiştir. Ayrıca Phillips eğrisinin doğruluğunun sınanması için yüzde 5 ve yüzde 6,54 oranında bir eşik düzeyi belirlenmiştir. Buna göre işsizlik oranı yüzde 5 'ten küçük olduğunda enflasyon ve işsizlik arasında negatif bir ilişki, işsizlik oranı yüzde 5-6,54 arasında olduğunda ise iki değişken arasında pozitif bir ilişki tespit edilmiştir. Son olarak işsizlik oranı yüzde 6,54 'ü aştığında ise iki değişken arasında herhangi bir ilişkinin olmadığ 1 sonucuna ulaşılmıştır.

\section{VERİ VE YÖNTEM}

Çalışmada Türkiye'de bulunan Düzey-2 bölgelerinde işsizlik ile enflasyon arasında bir ilişkinin olup olmadığı analiz edilmektedir. Çalışmada kullanılan veriler 2008-2017 yılları arasını kapsamaktadır. Analizde kullanılan 26 Düzey-2 bölgeleri Tablo 1'de gösterilmiştir. Türkiye'de İstatistiki Bölge Birimleri Sınıflandırması, 2002 tarihli Bakanlar Kurulu kararı ile kabul edilmiştir. Bu kararla birlikte Türkiye, Düzey 1 kapsamında 12 bölgeye, Düzey 2 kapsamında 26 bölgeye ve Düzey 3 kapsamında 81 bölgeye ayrılmıştır (Resmi Gazete, 2002, 24884 Sayı).

Tablo 1. Araştırma Kapsamında İncelenen Bölgeler

\begin{tabular}{|c|c|c|c|}
\hline $\begin{array}{l}\text { Bölge } \\
\text { Kodu }\end{array}$ & Bölge Adı & $\begin{array}{l}\text { Bölge } \\
\text { Kodu }\end{array}$ & Bölge Adı \\
\hline TR10 & İstanbul & TR71 & $\begin{array}{l}\text { Kırıkkale, Aksaray, Niğde, Nevşehir, } \\
\text { Kırşehir }\end{array}$ \\
\hline TR21 & Tekirdağ, Edirne, Kırklareli & TR72 & Kayseri, Sivas, Yozgat \\
\hline TR22 & Balıkesir, Çanakkale & TR81 & Zonguldak, Karabük, Bartın \\
\hline TR31 & İzmir & TR82 & Kastamonu, Çankırı, Sinop \\
\hline TR32 & Aydın, Denizli, Muğla & TR83 & Samsun, Tokat, Çorum, Amasya \\
\hline TR33 & Manisa, Afyon, Kütahya, Uşak & TR90 & $\begin{array}{l}\text { Trabzon, Ordu, Rize, Giresun, Artvin, } \\
\text { Gümüşhane }\end{array}$ \\
\hline TR41 & Bursa, Eskişehir, Bilecik & TRA1 & Erzurum, Erzincan, Bayburt \\
\hline TR42 & Kocaeli, Sakarya, Düzce, Bolu, Yalova & TRA2 & Ağrı, Kars, Iğdır, Ardahan \\
\hline TR51 & Ankara & TRB1 & Malatya, Elâzı̆ğ, Bingöl, Tunceli \\
\hline TR52 & Konya, Karaman & TRB2 & Van, Muş, Bitlis, Hakkâri \\
\hline TR61 & Antalya, Isparta, Burdur & TRC1 & Gaziantep, Adıyaman, Kilis \\
\hline TR62 & Adana, Mersin & TRC2 & Şanlıurfa, Diyarbakır \\
\hline TR63 & Hatay, Kahramanmaraş, Osmaniye & TRC3 & Mardin, Batman, Siirt, Şırnak \\
\hline
\end{tabular}

Çalışmada bağımlı değişken olarak işsizlik oranı (IO) bağımsız değişken

olarak ise enflasyon oranı (EO) kullanılmıştır. Veriler Türkiye İstatistik Kurumu'nun bölgesel istatistik verilerinden elde edilmiştir. Çalışmada Bayrak ve Kanca (2013)'nın Blanchard ve Gali (2007)'nin çalışmalarında kullandıkları modelin modifiye edilmiş hali baz alınmıştır.

Blanchard ve Gali (2007)'in ABD ekonomisi için kullandığı model şu şekildedir;

$$
\mathrm{w}=\mathrm{y}+\phi \mathrm{n}_{\mathrm{s}}+\varepsilon\left(\mathrm{n}_{\mathrm{s}}=\text { işsizlik oran1, } \mathrm{w}=\text { enflasyon oran }\right)
$$
gibidir;

Bayrak ve Kanca (2013)'ın modifiye ettikleri denklem ise aşağıdaki

Lunpt $=\alpha+\beta 1$ lenf $+\varepsilon t$ (lenf: tüketici fiyat endekslerindeki artış, lunpt= logaritması alınmış yıllık işsizlik oranı) 
$\mathrm{Bu}$ çalışmada bölgesel düzeyde işsizlik oranı ile enflasyon oranı arasındaki ilişkiyi test edebilmek amacıyla oluşturulan model aşağıdaki gibidir.

$$
\dot{I} O_{i t}=\beta_{0 i t}+\beta_{1 i t} E O_{i t}+\varepsilon_{i t}
$$

Denklemde, i yatay kesit birimlerini ifade ederken, $\mathrm{t}$ zaman boyutunu, $\varepsilon$ ise panel hata terimini ifade etmektedir.

Çalışmada işsizlik ve enflasyon arasındaki ilişkiyi analiz etmek için panel veri analizinden yararlanılmıştır. Panel veriler yatay kesit ve zaman boyutlarına göre mikro ve makro paneller olmak üzere ikiye ayrılmaktadır. Eğer yatay kesit boyutu (N) uzun, zaman boyutu (T) kısa ise bu tür panel veriler mikro panel olarak tanımlanmakta, yatay kesit boyutu ve zaman boyutu uzun ise bu tür panel veriler de makro panel olarak tanımlanmaktadır. Yapılacak çalışmada yatay kesit ve zaman boyutunun mikro panele mi ya da makro panele mi uygun olduğunun belirlenmesi önem arz etmektedir. Zira mikro ve makro paneller farklı ekonometrik işlemler gerektirmektedir (Baltagi, 2013: 1). Bireyler, firmalar ve hanehalk1 hakkında toplanan mikro panel veriler, makro panelle ölçülen benzer değişkenlerden daha doğru sonuçlar verebilir (Baltagi, 2005: 7). Ayrıca zaman boyutu kısa olduğundan dolayı mikro panellerde durağanlık varsayımının test edilmesi gerekmemektedir (Baltagi, 2013:1). Bu kapsamda çalışmada uygulanacak olan panel veri modelinde, 10 yıllık zaman boyutunun ve 26 Düzey-2 bölgesini içeren bir yatay kesit boyutunun olduğu göz önünde bulundurulduğunda yatay kesit bağımlılığ kullanılacak yöntemin tahmini için ise F testi, Breusch-Pagan LM (1980) ve Honda (1985) testleri uygulanmıştır. Ayrıca çalışmada, değişen varyans varsayımı, Breusch-Pagan-Godfrey Heteroscedasticity LM testi ile analiz edilirken; otokorelasyon varsayımı ise Baltagi ve Li (1991), Born ve Bretuing (2016) ve Bhargava, Franzini ve Narendranathan (1982)'ın Durbin-Watson testleri ile incelenmiştir.

\section{BULGULAR}

İşsizlik ile enflasyon arasındaki ilişkiyi saptamak için sabit etkiler modeli, rassal etkiler modeli ve havuzlanmış modelden hangisinin model tahminlemesi için kullanılacağına F testi, Breasch-Pagan LM (1980) ve Honda (1985) testleri yardımıyla karar verilmiştir. Bu testlere ilişkin analiz sonuçları Tablo 2'de gösterilmiştir.

Tablo 2. Model Tahminine Yönelik Analiz Sonuçları

\begin{tabular}{lcc}
\hline \multicolumn{1}{c}{ Test } & İstatistik & Olasılık değeri \\
\hline F-grup_sabit & 26.06917 & 0.000000 \\
F-zaman_sabit & 9.826669 & 0.000000 \\
F-iki yönlü_sabit & 21.89888 & 0.000000 \\
\hline LM-grup_rassal & 481.1682 & 0.000000 \\
LM-zaman_rassal & 9.357073 & 0.002221 \\
LM-iki yönlü_rassal & 490.5252 & 0.000000 \\
\hline Honda-grup_rassal & 21.93555 & 0.000000 \\
Honda-zaman_rassal & 3.058933 & 0.001111 \\
Honda-iki yönlü_rassal & 17.67377 & 0.000000 \\
\hline
\end{tabular}


Modelin havuzlanmış model mi yoksa sabit etkiler modeli ile tahmin edilip edilmeyeceğinin saptanması için F testi sonuçları dikkate alınmaktadır. Tablo 2'deki F testi sonuçlarına bakıldığında, olasılık değerinin kritik değer olan 0,05 değerinin altında olduğu görülmektedir. Yani sıfır hipotezi reddedilmiştir. $\mathrm{Bu}$ nedenle modelin havuzlanmış model yerine sabit etkiler modeli ile tahmin edilmesi çalışma açısından daha faydalı olacaktır. Bunun yanı sıra grup ve zaman etkilerinin varlığına ilişkin test istatistikleri değerlendirildiğinde hem zaman hem de grup etkisinin olduğu iki yönlü sabit etkinin olduğu tespit edilmiştir.

Tahmin modelinde rassal etkinin olup olmadığının saptanması için Breusch-Pagan LM (1980) ve Honda testleri yapılmıştır. Her iki test sonucuna göre, olasılık değerleri kritik değer olan 0,05 değerinden küçük olduğu için havuzlanmış model yerine rassal modelin tercih edilmesi gerektiği görülmektedir.

Tablo 2 sonuçlarına göre hem sabit etkilerin hem de rassal etkilerin tahmin yönteminde kullanılabileceği sonucu ortaya çıkmıştır. Ancak çalışmada incelenen dönem ve Düzey-2 bölgeleri dikkate alındığında, veri setinin belirli bir gruba ve belirli bir döneme ait olduğu görülmektedir. $\mathrm{Bu}$ nedenle modelin tahmin edilmesinde sabit etkiler modeli esas alınarak en küçük kareler yöntemi kullanılmıştır.

Çalışmadaki diğer bir aşama ise otokorelasyon ve değişen varyans sorununun olup olmadığının tespit edilmesidir. Otokorelasyon hata teriminin birbirini izleyen değerleri arasındaki anlamlı ilişkiyi açıklarken, değişen varyans ise bütün kesitler için hata terimlerinin varyanslarının farklı olması ve kovaryanslarının sıfır olmaması anlamına gelmektedir (Topaloğlu, 2018: 28).

Çalışmada, değişen varyans varsayımı, Breusch-Pagan-Godfrey Heteroscedasticity LM testi ile analiz edilirken; otokorelasyon varsayımı ise Baltagi ve Li (1991), Born ve Bretuing (2016) ve Bhargava, Franzini ve Narendranathan (1982)'nn Durbin-Watson testleri ile incelenmiştir. Sabit etkiler modeli esas alınarak hesaplanmış değişen varyans ve otokorelasyon test sonuçları Tablo 3'te gösterilmektedir.

Tablo 3. Sabit Etkiler Modeli İçin Değişen Varyans ve Otokorelasyon Test Sonuçları

\begin{tabular}{|c|c|c|}
\hline \multicolumn{3}{|l|}{ Değişen Varyans } \\
\hline & İstatistik & $\begin{array}{l}\text { Olasılık } \\
\text { Değeri }\end{array}$ \\
\hline Breusch-Pagan-Godfrey LMh_fixed & 421.6417 & 0.000000 \\
\hline $\begin{array}{l}\mathrm{H}_{\mathrm{o}}: \text { Değişen varyans yoktur } \\
\mathrm{H}_{1}: \text { Değişen varyans vardır. }\end{array}$ & & \\
\hline \multicolumn{3}{|l|}{ Otokorelasyon } \\
\hline Baltagi ve Li (1991) LMp-stat & 86.60432 & 0.000000 \\
\hline $\begin{array}{l}\mathrm{H}_{0}: \text { Otokorelasyon yoktur } \\
\mathrm{H}_{1}: \text { Otokorelasyon vardır. }\end{array}$ & & \\
\hline Born ve Bretuing (2016) LMp*-stat & 125.4294 & 0.000000 \\
\hline $\begin{array}{l}\mathrm{H}_{0}: \text { Otokorelasyon yoktur } \\
\mathrm{H}_{1}: \text { Otokorelasyon vardır }\end{array}$ & & \\
\hline Durbin-Watson & 0.727 & \\
\hline $\begin{array}{l}\mathrm{H}_{0}: \text { Otokorelasyon yoktur } \\
\mathrm{H}_{1}: \text { Otokorelasyon vardır }\end{array}$ & & \\
\hline
\end{tabular}


Sabit etkiler modeli için hesaplanmış değişen varyans ve otokorelasyon sonuçlarına bakıldığında, Breusch-Pagan-Godfrey LM testi olasılık değeri \%5'lik anlamlılık değerinden küçük olduğu görülmektedir. $\mathrm{Bu}$ durumda $\mathrm{H}_{0}$ hipotezi reddedilmektedir. Yani modelde değișen varyans söz konusudur. Otokorelasyon test sonuçlarına bakıldığında, Baltagi ve Li (1991) LMp-stat ve Born ve Bretuing LM (2016) testleri olasılık değerleri kritik değerlerin (\%1, \%5) altındadır. Dolayısıyla sıfır hipotezi reddedildiğinden dolayı modelde otokorelasyon sorunu vardır. Son olarak Durbin-Watson analizi sonuçlarına göre otokorelasyon sorununun var olup olmadığını anlayabilmek için 260 gözlem sayısı için DurbinWatson d testi tablo değerine bakmak gerekmektedir. Durbin-Watson d testi tablosunda $d$ istatistiğinin $\mathrm{d}_{\mathrm{PL}}$ (alt) sınır değeri 1.9336 ve $\mathrm{d}_{\mathrm{PU}}$ (üst) sınır değeri 1.9354 olarak tespit edilmiştir (Bhargava vd., 1982: 537). Durbin-Watson test istatistik değerinin 0.7273 olduğu görülmektedir $\left(0<\mathrm{d}<\mathrm{d}_{\mathrm{PL}}\right)$. Durbin-Watson sonuçlarına göre modelde otokorelasyon sorunu tespit edilmiştir.

Otokorelasyon ve değişen varyans sorununu giderebilmek için standart hataları düzelten dirençli tahminci kullanımını sağlayan White period testi kullanılmıştır. Ayrıca modelde tespit edilen otokorelasyon sonucunu tam olarak giderebilmek için modele AR süreci uygulanmıştır. Bu testlere göre yapılmış tahmin sonuçları Tablo 4'te gösterilmiştir.

Tablo 4. Sabit Etkiler Model Tahmin Sonuçları

\begin{tabular}{lrllr}
\hline Bağımlı Değişken: IO & & & \\
\cline { 2 - 5 } Açıklayıcı Değişken & Katsayı & Std. Hata & t-istatistiği & Olasılık değ. \\
\hline \hline EO & $\mathbf{- 0 . 1 3 4 5 2 1}$ & $\mathbf{0 . 0 3 2 8 1 7}$ & $\mathbf{- 4 . 0 9 9 0 6 6}$ & $\mathbf{0 . 0 0 0 1}$ \\
C & 11.05590 & 0.284559 & 38.85276 & 0.0000 \\
AR(1) & 0.596381 & 0.069335 & 8.601462 & 0.0000 \\
\hline \hline R-squared & 0.796255 & Mean dependent var & 10.02436 \\
Adjusted R-squared & 0.769551 & S.D. dependent var & 4.274423 \\
S.E. of regression & 2.051943 & Akaike info criterion & 4.387322 \\
Sum squared resid & 867.3566 & Schwarz criterion & 4.800780 \\
Log likelihood & -485.3167 & Hannan-Quinn criter. & 4.554028 \\
F-statistic & 29.81734 & & \\
Prob(F-statistic) & $\mathbf{0 . 0 0 0 0 0 0}$ & & \\
\hline \hline
\end{tabular}

Inverted AR Roots

.60

IO: işsizlik Oranı, EO: Enflasyon Oranı

Tablo 4'te Türkiye'deki Düzey-2 bölgelerinde işsizlikle enflasyon arasındaki ilişkinin sınanması için oluşturulan model doğrultusunda tahmin sonuçları görülmektedir. Analiz sonuçları değerlendirildiğinde, modelin bir bütün olarak anlamlılı̆̆ını ifade eden $\mathrm{F}$ istatistik olasılık değerinin anlamlı olduğu ve bağımsız değişkenin bağımlı değişkendeki değişimin \%79'unu $\left(\mathrm{R}^{2}\right)$ açıkladığı belirlenmiştir. Modelde işsizlik oranı ile enflasyon oranı arasında istatistiksel olarak anlamlı sonuçlar elde edilmiştir. Buna göre enflasyon oranlarındaki bir birimlik bir değişim işsizlik oranında yaklaşık olarak 0,13 birimlik bir azalmaya 
yol açacaktır. Dolayısıyla Türkiye'deki Düzey-2 bölgeleri için işsizlik ve enflasyon oranı arasında negatif bir ilişkinin olduğu ifade edilebilir.

\section{SONUÇ}

İşsizlik ve enflasyon arasındaki ilişki yarım asırdan fazladır tartışılmaktadır. Ancak iki makroekonomik gösterge arasındaki ilişki A. W. Phillips (1958) tarafından yapılan çalışmayla literatürde popülerlik kazanmıştır. Bu çalışmadan sonra literatürde işsizlikle enflasyon arasındaki ilişkiyi açıklamaya yönelik birçok çalışma yapılmıştır. Bu durum konunun hala önem arz ettiğini göstermektedir.

$\mathrm{Bu}$ çalışmada, Türkiye'deki Düzey-2 bölgeleri arasında işsizlik ve enflasyon arasındaki ilişki analiz edilmeye çalışılmışır. Çalışmanın bölgesel düzeyde yapılması çalışmayı Türkiye için önceki yapılan çalışmalardan farklı kılmaktadır. Çalışma 2008-2017 arası yılları kapsamaktadır. Çalışmada panel veri analizi yöntemi kullanılmıştır. Çalışmada kullanılan veri aralığı kısa olduğu için yatay kesit bağımlılığ 1 , homojenite ve durağanlık varsayımları analiz edilmemiştir. Modelde kullanılacak yöntemin tahmini için ise F testi, Breusch-Pagan LM (1980) ve Honda (1985) testleri uygulanmıştır. Ayrıca çalışmada, değişen varyans varsayım1, Breusch-Pagan-Godfrey Heteroscedasticity LM testi ile analiz edilirken; otokorelasyon varsayımı ise Baltagi ve Li (1991), Born ve Bretuing (2016) ve Bhargava, Franzini ve Narendranathan (1982)'in Durbin-Watson testleri ile incelenmiştir.

Çalışmada öncelikle çalışmanın yöntemi belirlenmiştir. Yapılan analizde hem sabit etkilerin hem de rassal etkilerin tahmin yönteminde kullanılabileceği sonucu ortaya çıkmıştır. Ancak çalışmada incelenen dönem ve Düzey-2 bölgeleri dikkate alındığında, veri setinin belirli bir gruba ve belirli bir döneme ait olduğu görülmektedir. $\mathrm{Bu}$ nedenle modelin tahmin edilmesinde sabit etkiler modeli esas alınarak en küçük kareler yöntemi kullanılmıştır. Daha sonra değişen varyans ve otokorelasyon analizi yapılmıştır. Çıkan sonuçlara göre otokorelasyon ve değişen varyans sorunu olduğu tespit edilmiştir. Otokorelasyon ve değişen varyans sorununu giderebilmek için standart hataları düzelten dirençli tahminci kullanımını sağlayan White period testi kullanılmıştır. Ayrıca modelde tespit edilen otokorelasyon sonucunu tam olarak giderebilmek için modele AR süreci uygulanmıştır.

Analiz sonuçları değerlendirildiğinde, modelin bir bütün olarak anlamlığını ifade eden $\mathrm{F}$ istatistik olasılık değerinin anlamlı olduğu ve bağımsız değişkenin bağımlı değişkendeki değişimin \%79'unu $\left(\mathrm{R}^{2}\right)$ açıkladığı belirlenmiştir. Modelde işsizlik oranı ile enflasyon oranı arasında istatistiksel olarak anlamlı sonuçlar elde edilmiştir. Buna göre enflasyon oranlarındaki bir birimlik bir değişim işsizlik oranında yaklaşık olarak 0,13 birimlik bir azalmaya yol açacaktır. Dolayısıyla Türkiye'deki Düzey-2 bölgeleri için işsizlik ve enflasyon oranı arasında negatif bir ilişkinin olduğu ifade edilebilir.

Türkiye'de bölgeler arasında sosyo-ekonomik farklılıkların olduğu aşikardır. Bu farklılıkların nedenleri arasında işsizlik, gelir dağılımı eşitsizliği, düşük eğitim seviyesi gibi faktörler ön plana çıkmaktadır. Bu sorunların çözülmesi 
için devlet tarafından yatırımlar yapılmaktadır. Ancak bu yatırımlar yatırımın yapıldığı bölgelerde istenilen etkinliği sağlamamaktadır. Üretimin artırılmasına yönelik yapılan yatırımların bölge niteliklerine uygun ve istihdam arttırıcı bir yapıda olması hem işsizliğin azalmasına yol açacak hem de bireylerin refahının artmasından dolayı ülke refahının artmasına katkı sunacaktır. Ayrıca politika yapıcıların fiyat istikrarına yönelik uygulayacağı politikalarda Türkiye'deki bölgelerin ekonomik özelliklerini göz önünde bulundurmaları fiyat istikrarının sağlanmasında olumlu yönde bir etki yaratabilir. Örneğin gıda enflasyonu sorununun çözümünde tarımla uğraşan bölgelerde üreticilere yönelik destekler fiyat istikrarını sağlayıcı bir etki doğurabilir. Sonuç olarak hem enflasyon oranının hem de işsizliğin artmasını önlemeye yönelik uygulanacak politikalarda bölgeler arasındaki gelişmişlik farkının dikkate alınması ekonomik istikrarın sağlanmasına katk1 sunabilir.

\section{KAYNAKÇA}

Akkuş, G.E. (2012). Phillips Eğrisi: Enflasyon-İşsizlik Değiş-Tokuşu Teorik Bir İnceleme. İstanbul Üniversitesi İktisat Fakültesi Mecmuast, 62 (2): 99-151.

Alisa, M. (2015). The Relationship between Inflation and Unemployment: A Theoretical Discussion about the Phillips Curve, Journal of Business and Economics, 3(2): 89-97.

Arabac1, O., Eryiğit, K. Y. (2012). A Thresold Regression Estimation of Phillips Curve: Turkey Case, Eskişehir Osmangazi Üniversitesi IİBF Dergisi, 7:29-47.

Aşırım, O. (1995), Output Inflation Tradeoff: Evidence From Turkey, The Central Bnak of The Republic of Turkey Discussion Paper No: 9506 p.135-142.

Baltagi, B.H. (2005). Econometric Analysis of Panel Data, Third Edition, West Sussex: John Wiley Sons Ltd.

Baltagi, B.H. (2013). Econometric Analysis of Panel Data, Fifth Edition, Chichester: John Wiley Sons Ltd.

Baltagi, B. H., Li, Q. (1991), A Joint Test for Serial Correlation and Random İndividual Effects, Statics \& Probability Letters, 11: 277-280

Bayrak, M., Kanca, O.C. (2013). Türkiye'de Philips Eğrisi Üzerine Bir Uygulama, Eskişehir Osmangazi Üniversitesi İ̈BF Dergisi, 8(3): 97-115.

Bhargava, A., Franzini, L., Narendranathan, W. (1982). Serial Correlation and the Fixed Effects Model, The Review of Economic Studies, 49(4): 533-549.

Blanchard, O., Gali, J. (2007), "Real Wage Rigidities and the New Keynesian Model", Journal of Money, Credit and Banking, 39 (1): 35-64.

Born, B., Breitung, J. (2016), Testing for Serial Correlation in Fixed-Effects Panel Data Models, Econometric Reviews, 35(7): 1290-1316.

Breusch, T.S., Pagan, A.R. (1980). The Lagrange Multiplier Test and Its Applications to Model Specification in Econometrics, The Review of Economic Studies, 47(1): 239-253.

Büyükakın, T. (2008). Phillips Eğrisi: Yarım Yüzyıldır Bitmeyen Tartı̧̧ma, İ.Ü. Siyasal Bilgiler Fakültesi Dergisi, 39: 133-159.

Çevik, F.S. (2005). Beklentilerin Rolü ve Phillips Eğrisi, Mevzuat Dergisi, 8(95), https://www.mevzuatdergisi.com/2005/11a/01.htm\# (Erişim Tarihi: 02.03.2019).

Ewing, B. T., Seyfried, W. L. (2003). Modeling The Phillips Curve : A Time- Varying Volatility Approach, Applied Econometrics and International Development, AEEADE, 3-2: 7-24.

Fisher, I. (1973). I Discovered the Phillips Curve: A Statistical Relation Between Unemployment and Price Changes, Journal Of Political Economy, 81(2): 496-502.

Fitzgerald, T. J. and Nicolini J.P. (2014). Is There a Stable Relationship between Unemployment and Future Inflation? Evidence from U.S. Cities, Federal Reserve Bank of Minneapolis Research Department, Working Paper No: 713, pp.1-32, https://www.minneapolisfed.org/research/wp/wp713.pdf (Erişim Tarihi: 13.03.2019). 
Friedman, M. (1968). The Rol of Monetary Policy, The American Economic Review, 58(1): 1-17.

Friedman, M. (1977). Nobel Lecture: Inflation and Unemployment, The Journal of Political Economy, 85(3): 451-471.

Ho, Sin-Yu and Iyke B.N. (2018). Unemployment and Inflation:Evidence of a Nonlinear Phillips Curve in the Eurozone, Munich Personal Repec Archive, Paper No: 87122, pp. 1-16. https://mpra.ub.uni-muenchen.de/87122/ (Erişim Tarihi: 10.02.2019).

Honda, Y. (1985). Testing The Error Components Model With Non-Normal Disturbances, Review of Economic Studies, 52:681-690.

Humprey, T.M. (1985a). The Evolution and Policy Implications of Phillips Curve Analysis, Economic Review, Federal Reserve Bank of Richmond, p. 3-22, https://www.richmondfed.org//media/richmondfedorg/publications/research/economic_review/1985/pdf/er710502.pdf, (Erişim Tarihi: 25.02. 2019).

Humprey, T.M. (1985b). The Early History of The Phillips Curve, Economic Review, Federal Reserve Bank of Richmond, p. 17-24, https://www.richmondfed.org//media/richmondfedorg/publications/research/economic_review/1985/pdf/er710201.pdf, (Erişim Tarihi: 25.02. 2019).

Karacan, R. (2018). Phillips Eğrisi Yaklaşımı ile Türkiye'de Enflasyon ve İşsizlik Arasındaki Nedensellik İlişkisi, Social Mentality and Researcher Thinkers Journal, 4(10): 242-249.

Karahan, P., Uslu, N. Ç. (2018). A Dynamic Analysis on the Validity of the Phillips Curve for Turkey, Finans Politik \& Ekonomik Yorumlar, 55(636): 89-99.

Kitov, I., (2007). Inflation, Unemployment, Labor Force Change in European Countries, Munich Personal RePEc Archive, pp. 1-68. https://mpra.ub.uni-muenchen.de/14557/ (Erişim Tarihi: 04.03.2019).

Korkmaz, S. (2010). Yeni Keynesyen Phillips Eğrisinin Türkiye’ye Uygulanması, ZKÜ Sosyal Bilimler Dergisi, 6(11): 141-162.

Kuştepeli, Y. (2005). A Comprehensive Short-run Analysis of a (possible) Turkish Phillips Curve, Applied Economics, 37: 581-591.

Lipsey, R.G. (1960). The Relation between Between Unemployment and the Rate of Change of Money Wage Rates in the United Kingdom, 1862-1957: A Further Analysis, Economica, 27(105): 1-31.

Mayes, D. and Matti V. (2006). The Relation between Inflation and Regional Unemployment and Sectoral Income Growth Dispersion: Evidence from EU-Countries, the Journal of Economic Asymetries, 3(2): 83-102.

Musso, A., Stracca, L., Dijk, D. V. (2009). Instability and Nonlineraity in the Euro-area Phillips Curve, International Journal of Central Banking, 5(2): 181-212.

Önder, A.Ö. (2006). The Stability of the Turkish Phillips Curve and Alternative Regime Shifting Models, Ege Universty Working Papers in Economics, Working Paper No: 06/02, p.1-23.

Phelps, E.S. (1967). Phillips Curves, Expectations of Inflation and Optimal Unemployment over Time, Economica, 34(105): 254-281.

Phillips, A.W. (1958). The Relation Between Unemployment and the Rate of Change of Money Wage Rates in the United Kingdom, 1861-1957. Economica, 25(100): 283-299.

Resmi Gazete (22 Eylül 2002). Sayı: 24884, 2002/4720 Bölgesel İstatistiklerin Toplanmasl, Geliştirilmesi, Bölgelerin Sosyo-Ekonomik Analizlerinin Yapılması, Bölgesel Politikaların Çerçevesinin Belirlenmesi ve Avrupa Birliği Bölgesel İstatistik Sistemine Uygun Karşılaş̧ırılabilir İstatistiki Veri Tabanı Oluşturulması Amacıyla Ülke Çapında İstatistiki Bölge Birimleri Sinıflandırmasının Tanımlanmasına Ilisskin Hakkında Karar.

Samuelson, P.A., Solow, R.M. (1960). Analytical Aspects of Anti-Inflation Policy, The American Economic Review, 50(2): 177-194.

Tabar, Ç., Çetin, I.K. (2016). Türkiye Ekonomisi Özelinde Phillips Eğrisi Analizi, Journal of Life Economics, 3(4): 79-100.

Topaloğlu, E. E. (2018). Bankalarda Finansal Kırılganlığı Etkileyen Faktörlerin Panel Veri Analizi ile Belirlenmesi, Eskişehir Osmangazi Üniversitesi IIIBF Dergisi, 13(1):15-38.

Türkiye İstatistik Kurumu (TÜİK), Bölgesel İstatistikler, https://biruni.tuik.gov.tr/bolgeselistatistik. 
Uysal, D., Erdoğan, S. (2003). Enflasyon ile İşsizlik Oranı Arasındaki İlişki ve Türkiye Örneği (19802002), SÜ İIBF Sosyal ve Ekonomik Araştırmalar Dergisi, 3(6): 35-47.

Vermeulen, J.C. (2017). Inflation and unemployment in South Africa: Is the Phillips curve still dead?, Southern African Business Review, 21: 20-54.

\section{SUMMARY}

Unemployment and inflation rates have an important place among macroeconomic indicators. Because both two positive or negative change of indicators affect the country's economy directly or indirectly. Therefore, the relation between unemployment and inflation has been debated for more than half a century. But the relation between two macroeconomic indicators has won popularity in the literature with the study of A. W. Phillips (1958). After this study, many scientific articles have been published in order to investigate the relation between unemployment and inflation. This shows that the topic has a great importance.

This study aims to analyze relation between unemployment and inflation for NUTS-2 regions in Turkey. Having been studied for the NUTS-2 regions in Turkey separates this study from previous studies. This study analyses the years between 2008-2017. Unemployment rates are used as dependent variables and inflation rates are used as independent variables in this study. The data which is used in this study is obtained from the regional statistic data from TUIK. Panel data analyze is used in this study. Cross sectional dependency, stationarity and homogeneity assumptions are not taken into account because of the short data range. To estimate the method of the study, F test, Breusch-Pagan LM and Honda tests are employed. Besides, while heteroscedasticity is analyzed with BreuschPagan-Godfrey Heteroscedasticity LM test, autocorrelation is analyzed with Baltagi and Li (1991), Born and Bretuing (2016) and Bhargava, Franzini and Narendranathan's (1982) Durbin-Watson tests.

Firstly, the method of the study is specified. According to the F test result, it is obtained that the fixed effect model is valid because the probability value (pvalue $=0,000$ ) is lower than $\% 5$. Also, random effect method is tested by applying Breusch-Pagan LM (1980) and Honda (1985) tests. According to both BreuschPagan LM (1980) and Honda (1985) tests result, it is obtained that the random effect model is valid because the probability value ( $\mathrm{p}$-value $=0,000)$ is lower than $\% 5$. As a result, both random effects and fixed effects can be used in estimation method. But when the examined period and NUTS-2 regions are taken into account, data set belongs to specific group and period. Therefore, the study is analyzed according to the least square based fixed-effects model.

Moreover, heteroscedasticity and autocorrelation are analyzed. In this model when the results are analyzed for the fixed-effect model, heteroscedasticity problem is identified since the p-value is lower than $\% 5$ according to the BreuschPagan-Godfrey LM test. Also, when the results are checked for autocorrelation problem in this model, since the $\mathrm{p}$-value is ( $\mathrm{p}$-value $=0,000)$ according to Baltagi and Li (1991) LMp-stat test and Born and Bretuing (2016) LM test, autocorrelation problem exist. As a result, both heteroscedasticity and autocorrelation problem are 
identified. White period test which allows using robust estimator in order to correct standard errors is applied to fix autocorrelation and heteroscedasticity problem in the model. Additionally, AR process is applied to the model to fully overcome the identified autocorrelation problem.

When the results of the analysis are evaluated, it is determined that $\mathrm{F}$ Statistic probability value which indicates the significance of the model as a whole, is significant and independent variable explains \%79 of the variation in the dependent variable. In the model, statistically significant results are obtained between unemployment and inflation rate. Accordingly, there is a negative relation between unemployment rate and inflation rate in NUTS-2 regions. 